ОПРЕДЕЛЕНИЕ КОНЦЕНТРАЦИИ РОПИВАКАИНА В ВЕНОЗНОЙ КРОВИ ПРИ ПРОВЕДЕНИИ ДЛИТЕЛЬНОЙ АНАЛЬГЕЗИИ ПОСЛЕОПЕРАЦИОННОЙ РАНЫ

(C) А.А. Винокурова ${ }^{1,2,3}$, М.А. Гофенберг ${ }^{1,4,5}$, С.Г. Дубровин ${ }^{2}$, В.А. Багин ${ }^{1,2}$, В.А. Руднов ${ }^{1,2}$

Уральский государственный медицинский университет, Екатеринбург, Российская Федерация (1)

Городская клиническая больница №40, Екатеринбург, Российская Федерация (2)

Европейский медицинский центр «УГМК-Здоровье», Екатеринбург, Российская Федерация (3)

Областная наркологическая больница, Екатеринбург, Российская Федерация (4)

Свердловская областная клиническая психиатрическая больница, Екатеринбург,

Российская Федерация (5)

Цель. Определение концентраций общего ропивакаина в венозной крови при использовании выбранной схемы длительной анальгезии послеоперационной раны после операции кесарева сечения.

Материалы и методы. В исследование были включены 47 пациенток после операции кесарева сечения, которым во время ушивания лапаротомической раны под апоневроз мышц живота устанавливался мультиперфорированный катетер для длительной послеоперационной анальгезии. Про помощи инфузионного насоса $0,2 \%$ раствор ропивакаина вводился с постоянной скоростью 4 мл/ч, общий объем 200,0 мл. Забор крови путем пункции периферической вены производился в контрольных точках через 30 мин, 24 ч и через 48 ч после начала введения раствора. Количественное определение концентрации общего (свободного и связанного с белками плазмы) ропивакаина плазмы венозной крови проводилось использованием газового хроматографа с масс-селективным детектором.

Результаты. Наибольшие полученные концентрации общего ропивакаина венозной крови были зафиксированы через 48 ч Me $(\mathrm{Q} 1 ; \mathrm{Q} 3)=0,053(0,043 ; 0,071)$ - что значительно ниже минимальных потенциально токсических. Также не было зафиксировано ни одного случая проявления клинических признаков системной токсичности местных анестетиков. Не было выявлено статистически достоверной корреляции между массой тела, ростом, индексом массы тела и концентрацией общего ропивакаина в венозной крови.

Заключение. Данное исследование позволило подтвердить безопасность выбранной схемы введения раствора местного анестетика, так как потенциально токсичные концентрации общего ропивакаина в венозной крови не были достигнуты ни у одной из пациенток, включенных в исследование.

Ключевые слова: ропивакаин; местные анестетики; длительная анальгезия раны; послеоперационное обезболивание; системная токсичность. 


\title{
DETERMINATION OF CONCENTRATION OF ROPIVACAINE IN VENOUS BLOOD IN PROLONGED ANALGESIA OF POSTOPERATIVE WOUND
}

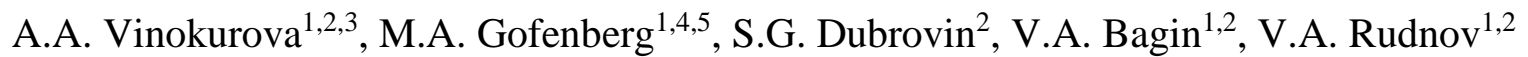

Ural State Medical University, Ekaterinburg, Russian Federation (1)

Municipal Clinical Hospital №40, Ekaterinburg, Russian Federation (2)

European Medical Center USMC-Health, Ekaterinburg, Russian Federation (3)

Regional Narcological Hospital, Ekaterinburg, Russian Federation (4)

Sverdlovsk Regional Clinical Psychiatric Hospital, Ekaterinburg, Russian Federation (5)

Aim. Determinations of concentrations of total ropivacaine in venous blood with use of the selected scheme of prolonged analgesia of the postoperative wound after cesarean operation.

Materials and Methods. The study involved 47 female patients after cesarean operation in whom during suturing of the laparotomy wound a multiperforated catheter was installed under aponeurosis of the abdominal muscles for a prolonged postoperative analgesia. With use of infusion pump, $0.2 \%$ ropivacaine solution was introduced at constant speed $4 \mathrm{ml} / \mathrm{h}$ with the total amount $200.0 \mathrm{ml}$. Blood was taken by puncture of the peripheral vein in control points in $30 \mathrm{~min}, 24$ hours and 48 hours after the start of injection of the solution. The quantitative determination of the concentration of the total ropivacaine of venous blood plasma (free and bound with plasma proteins) was conducted using gas chromatograph with mass-selective detector.

Results. The highest concentrations of the total ropivacaine of venous blood were recorded in 48 hours Me (Q1; Q3)=0.053 (0.043; 0.071) which was significantly lower than minimal potentially toxic concentrations. Also not a single case of appearance of clinical signs of systemic toxicity of local anesthetics was recorded. No statistically reliable correlation was found between body mass, height, body mass index and concentration of total ropivacaine in blood.

Conclusion. The given study permitted to confirm safety of the selected scheme of introduction of the solution of local anesthetic, since no potentially toxic concentrations of the total ropivacaine were reached in venous blood in a single patient included into the study.

Keywords: ropivacaine; local anesthetics; prolonged wound analgesia; postoperative analgesia; systemic toxicity.

Один из важных компонентов, обеспечивающих гладкое течение послеоперационного периода - достаточный уровень обезболивания, который в акушерском стационаре имеет еще и социальную значимость, так как позволяет обеспечить раннюю активизацию, возможность самообслуживания и ухода за ребенком, скорейшее начало грудного вскармливания. Современная тенденция - это поиск наименее инвазивных и простых в исполнении методов, сопровождающихся минимумом побочных эффектов. В частности, продленная (<24 ч)/длительная (>24 ч) локальная анальгезия послеоперационной раны растворами местных анестетиков (МА), может быть хорошей альтернативой для контингента пациентов, которым нежелательно назначение высоких доз наркотических анальгетиков, а выполнение эпидуральной анестезии ограничено клинической ситуацией (т.е. противопоказано или технически невозможно).

Методики введения местных анестетиков в рану широко используются уже давно и во многих исследованиях демонстрируют свою безопасность и эффективность. Так в метаанализе, включающем 594 исследования за 1966-2006 гг. было показано, что длительное введение растворов 
местных анестетиков через внутрираневые катетеры достоверно позволяет добиться сокращения длительности пребывания пациентов в стационаре, снижения потребления наркотических анальгетиков и, соответственно уменьшения количества неблагоприятных опиоид-индуцированных побочных эффектов [1].

Однако, на сегодняшний день не существует единой унифицированной схемы проведения длительной локальной анальгезии (ДЛА). Выбор местного анестетика и адъювантов, концентрация раствора и объем, и скорость введения определяются авторами самостоятельно и ограничены только особенностью регистрации препарата в конкретной стране. Так большинство исследователей используют ропивакаин в качестве препарата выбора, ввиду большей длительности сенсорного блока. Было показано, что использование ропивакаина ассоциировано с меньшей частотой развития побочных эффектов со стороны ЦНС и сердечно-сосудистой системы, и он на $25 \%$ менее токсичен, чем бупивакаин [2].

Что касается количества препарата, то некоторые исследователи предлагают рассчитывать объем раствора исходя из роста и/или массы тела пациента, предполагая, с одной стороны, различную площадь поверхности, которую необходимо ввести в контакт с местным анестетиком. С другой стороны, при использовании фиксированного объема и высокой концентрации раствора нельзя забывать о рисках системной токсичности, особенно у пациентов с дефицитом массы тела. P.H. Rosenberg, et al. [3] предположили, что рекомендуемые дозы местных анестетиков должны быть специфицированы для конкретной блокады и выбранного участка. Предыдущие исследования показали, что васкуляризация тканей в области введения препарата является основной детерминантой системного всасывания местных анестетиков [4,5]. Также можно предположить, что абсорбция анестетика из раневой поверхности будет более интенсивная, чем из зоны неповрежденных тканей.
Интересным фактом является то, что на сегодняшний момент не существует однозначного ответа на вопрос: какая концентрация местного анестетика в крови является токсичной. Большинство рекомендаций основано на экстраполяции результатов, полученных в экспериментах на животных, описаниях случаев, фармакокинетических данных и измерениях концентраций в крови. Одно из первых исследований по определению пороговых концентраций местных анестетиков было проведено в 1997 г. Knudsen, et al. на здоровых добровольцах путем введения им внутривенно растворов ропивакаина и бупивакаина до появления симптомов системной токсичности [2]. Именно на значения, полученные в этом эксперименте, опирается сегодня большинство исследователей, используя их как эталон. Для ропивакаина токсической определена общая концентрация в венозной крови в $2,2(0,5-3,2)$ мкг/мл.

В систематическом обзоре 15 исследований из 4 баз данных (MEDLINE, EMBASE, Кокрановский центральный peгистр контролируемых испытаний и PubMed), посвященных оценке системных концентраций местных анестетиков после блокад поперечного пространства живота и влагалища прямой мышцы живота у 33 из 381 пациентов средние пиковые концентрации местных анестетиков превышали предполагаемые токсические пороги, и лишь у троих из них были зафиксированы легкие побочные эффекты. Случаев судорог или кардиальных осложнений не наблюдалось [6].

В одном из крупнейших метаанализов, включающем 594 исследования, посвященных эффективности и безопасности продленной и длительной локальной анальгезии с участием 2141 пациента, не было зафиксировано ни одного случая жизнеугрожающей системной токсичности [1].

Таким образом, актуальным является поиск оптимальных дозировок и режимов введения растворов местных анестетиков в рамках ограничений, установленных в нашей стране. В России максимальные 
рекомендуемые дозы ропивакаина (по данным государственного реестра лекарственных средств, 2018 г.): разовая 300 мг, суточная 800 м), почасовая для продленного обезболивания $28 \mathrm{мг/ч.}$

Цель - определение концентраций общего ропивакаина в венозной крови при использовании выбранной схемы ДЛА (введение ропивакаина $0,2 \%-200,0$ мл в течение 48 ч) после операции кесарева сечения.

\section{Материалы и методы}

Дизайн исследования - одномоментное проспективное обсервационное.

Пациенткам, отвечающим критериям включения и давшим согласие на участие в исследовании, получающим дополнительное обезболивание в виде ДЛА был произведен однократный забор венозной крови с целью контроля концентрации общего (свободного и связанного с белками плазмы) ропивакаина.

Получено одобрение локального этического комитета МАУ ГКБ№40, и от каждой пациентки было получено письменное информированное согласие на участие в исследовании и использовании их биопроб.

Критерии включения: пациентки, получающие в послеоперационном обезболивании после операции кесарева сечения дополнительное обезболивание в виде ДЛА раствором ропивакаина. По классификации Американского общества анестезиологов (ASA) в пересмотре 2014 г., класс II (пациентки с нормально протекающей беременностью, а также с наличием легких системных заболеваний, без существенных функциональных ограничений) [7].
Критерии исключения: возраст менее 18 лет, ASA III, IV, V, заболевания и состояния, сопровождающиеся почечной и/или печеночной недостаточностью, прием препаратов, ингибирующих цитохромы CYP1A2 или CYP3А4 (в т.ч. атазанавир, циметидин, ципрофлоксацин, эноксацин, флувоксамин, мексилетин, такрин, тиабендазол, зилеутон, интраконазол, кетоконазол, верапамил, тролеандомицин), наличие аллергии на препараты местных анестетиков, ИМТ менее 17 или более 40 кг/м², отказ пациентки от участия в исследовании.

Группы были сформированы в зависимости от получаемой схемы послеоперационного обезболивания, соответствующее клиническим рекомендациям министерства здравоохранения РФ по ведению родильниц после абдоминального родоразрешения [8]:

Исследуемая группа: кеторол 30 мг х 3p/сут в/м + парацетамол (1000 мг х 4p/сут перорально) + трамадол (100 мг в/м по требованию) + ДЛА ропивакаином $0,2 \%-$ 200,0 мЛ -48 ч.

Контрольная группа: кеторол 30 мг х 3p/сут в/м + парацетамол (1000 мг х 4p/сут перорально) + трамадол (100 мг в/м по требованию).

Характеристика включенных пащиенток: Средние значения (здесь и далее в виде $\mathrm{Me}(\mathrm{Q} 1 ; \mathrm{Q} 3))$ для общей популяции $(\mathrm{n}=47) \quad 32,0 \quad(30,0 ; 36,0)$ года; 71,0 $(69,0$; $78,0)$ кг; 26,6 $(25,7 ; 28,4)$ кг/ $\mathrm{M}^{2}$ соответственно. Исследуемые группы были сравнимы по возрасту, массе тела и индексу массы тела (ИМТ):

Таблица 1

\section{Антропометрические данные пациенток по группам}

\begin{tabular}{|c|c|c|c|}
\hline & \multicolumn{2}{|c|}{ Группы } & \multirow[b]{2}{*}{$\mathbf{p}$} \\
\hline & исследуемая, $\mathbf{n = 2 2}$ & контроль, $\mathrm{n}=25$ & \\
\hline возраст, лет & $31,5(25,0 ; 41,0)$ & $32,0(26,0 ; 44,0)$ & 0,271 \\
\hline масса тела, кг & $72,5(59,0 ; 94,0)$ & $71,0(65,0 ; 88,0)$ & 0,341 \\
\hline ИМТ, кг/м² & $27,0(19,9 ; 31,2)$ & $26,4(21,5 ; 29,8)$ & 0,741 \\
\hline
\end{tabular}

Операция кесарева сечения проводилась в условиях спинальной анестезии раствором бупивакаина 5\% - 2 мл (Маркаин
Спинал Хэви Astra Zeneka, Швеция) без адъювантов на уровне L2-L3 в положении пациентки лежа на боку. 
Пациенткам исследуемой группы во время ушивания операционной раны под апоневроз мышц передней брюшной стенки хирургом устанавливался мультиперфорированный катетер из набора для регионарной анестезии InfiltraLong (Pajunk GmbH Medizintechnologie, Германия). Через 3 часа после выполнения спинальной анестезии вводилась нагрузочная доза $0,2 \%$ ропивакаина - 8 мл, (Fresenius Kabi Deutschland, GmbH, Германия, Fresenius Kabi Norge, AS, Норвегия). Дальнейшая введение препарата проводилось инфузионным насосом (Mini Rhythmic Evolution, Micrel Medical Devices S.A., Греция) со скоростью 4 мл/ч в течение 48 часов.

Забор образцов. Забор крови производился через 30 мин, 24 ч и через 48 ч после введения нагрузочной дозы путем венепункции поверхностных вен верхних конечностей в одноразовые герметичные вакуумные пробирки 4,5 мл с цитратом натрия 3,2\% (Vacutainer, Becton Dickinson). Центрифугированную плазму хранили при $-20^{\circ} \mathrm{C}$ до анализа.

Построение калибровочного гра$ф u к a$. Для построения калибровочной зависимости готовили серию из 5 стандартных растворов ропивакаина в плазме крови, содержащих от 0,01 до 10 мкг исследуемого вещества в 1 мл пробы. В качестве внутреннего стандарта использовали водный раствор лидокаина с концентрацией 100 мкг/мл.

Анализ образиов. К 0,5 мл образцов плазмы крови добавляли 0,02 мл внутреннего стандарта, 0,01 мл насыщенного раствора карбоната натрия и 0,7 мл ацетонитрила. Затем дважды проводили экстракционное вымораживание при температуре $-18-20^{\circ} \mathrm{C}$. Объединенные ацетонитрильные извлечения упаривали в токе теплого воздуха. Сухой экстракт реконструировали в 0,1 мл ацетонитрила. 1 мкл полученного раствора вводили в испаритель газового хроматографа.

Метод исследования. Количественное определение общей концентрации ропивакаина проводилось использованием газового хроматографа с масс-селективным детектором GCMS-QP2010 Ultra (Шимадзу, Япония).
Режим работы газового хроматографа с масс-селективным детектором. Скорость потока газа-носителя (гелий) через колонку 1,2 мл/мин, режим работы split/splitless (деление потока 4:1, с задержкой включения 10 мин после ввода пробы). Температура испарителя хроматографа и интерфейса детектора составляла 280 и $300^{\circ} \mathrm{C}$ соответственно. Разделение проводили с использованием кварцевой капиллярной колонки MEGA-17MS (толщина неподвижной фазы 0,25 мкм, длина 30 м, внутренний диаметр 0,25 мм). Температура колонки: начальная $90^{\circ} \mathrm{C}$ в течение 0,5 мин, прогрев до $295^{\circ} \mathrm{C}$ со скоростью программирования 15 град/мин, выдержка при конечной температуре 15,83 мин. Энергия ионизации 70эВ. Напряжение на умножителе масс-спектрометрического детектора устанавливали равной величине автоматической настройки детектора. Регистрация масс-спектров производилась в режиме селективного ионного мониторинга. В качестве характеристических для лидокаина были выбраны ионы с m/z 86, 58, 87, 30, 72, $120,56,77,91$, для ропивакаина - ионы с m/z 126, 127, 84, 56, 96, 43, 124, 77. Количественную обработку хроматограмм проводили с использованием программного обеспечения GCMS Solution (версия 4.5.SP1).

Оценка боли. В послеоперационном периоде субъективное восприятие боли оценивалось в покое и при движении с использованием стандартной числовой рейтинговой шкалы (NRS-11), где 0 - отсутствие боли, а 10 - наиболее сильная боль, какую только можно было представить с 4часовыми интервалами после операции до 48 часов после операции.

Статистическая обработка. Для обработки данных использовались методы описательной статистики при помощи программы EZR on R commander v. 1.38. Учитывая малый объем выборки, при анализе количественных данных меры среднего уровня представлены в виде медианы (Ме), меры рассеяния - в виде интерквартильного размаха (IQR). Для проверки нормальности распределения выборки использовался $\mathrm{W}$-критерий Шапиро-Уилка. 
Для количественных переменных, которые не отвечали критериям нормального распределения, применяли непараметрические методы анализа. Для сравнения двух независимых выборок использовали критерий Манна-Уитни.

При оценке статистической значимости различий между группами с категориальными переменными использовался критерий $\chi 2$ Пирсона.

Наличие или отсутствие линейной связи между количественными показателями подтверждали посредством расчета коэффициента корреляции Спирмена.

\section{Результаты и их обсуждение}

В течение всего времени проведения ДЛА не было выявлено ни одного случая появления симптомов, связанных с системной токсичностью ропивакаина (в том числе: онемение губ и языка, нарушения слуха и зрения, дизартрия, одышка, головокружение, мышечные подергивания, ригидность мышц, металлический привкус во рту, приливы жара, нарушения сердечного ритма, изменение состояния сознания, эйфория или судороги). Важно отметить, что инфекционных и иных осложнений в области операционной раны зарегистрировано не было. Потенциальный риск развития раневой инфекции, вероятно, является основным опасением, сдерживающим оперирующих хирургов от широкого применения длительной локальной анальгезии, так как предполагается, что катетер, будучи инородным телом может препятствовать нормальному заживлению раны, а вводимый раствор повышает риски контаминации микробными агентами. Однако данные предположения опровергаются научными данными. В метаанализах А.А. Gupta, et al. [9], S.S. Liu, et al. [10,1] было показано, что использование имплантируемых катетеров не только не увеличивает риск развития раневой инфекции, но и снижает риск расхождения краев и несостоятельности раны. Учитывая возрастающую антибиотикорезистентность микроорганизмов, бактерицидные и бактериостатические свойства местных анестетиков [11-
13] сегодня представляют большой интерес для ученых и даже рекомендуются в некоторых современных протоколах по профилактике и лечению инфекции в области операционной раны [12-14].

При оценке клинической эффективности ДЛА установлено снижение интенсивности послеоперационного болевого синдрома в среднем на 1,2 балла по шкале NRS-11. Статистически значимые различия были получены в контрольных точках 4 ч $(\mathrm{p}=0,010), 8$ ч $(\mathrm{p}=0,001), 24$ ч $(\mathrm{p}=0,042)$ при движении. Слабый эффект ДЛА в покое можно объяснить тем, что методика не купирует висцеральный компонент боли, который доминирует при отсутствии напряжения мышц передней брюшной стенки. Тогда как при активизации пациентки из зоны операционной травмы повышается афферентная импульсация, которую можно локально блокировать действием местных анестетиков.

Для оценки безопасности выбранной схемы была проведена токсикометрия образцов венозной крови в контрольных точках: через 30 мин, 24 и 48 ч после введения нагрузочной дозы для определения концентрации общего (свободного и связанного с белками плазмы) ропивакаина.

Несмотря на то, что всем пациенткам, независимо от антропометрических показателей, вводилось одинаковое количество анестетика, не было выявлено статистически достоверной корреляции между массой тела, ростом, ИМТ и концентрацией общего ропивакаина в венозной крови. Ввиду этого, не кажется целесообразным индивидуальный подбор дозы путем предварительных подсчетов по весоростовым характеристикам.

В настоящее время отсутствуют доказательно основанные критерии, которые однозначно предписывали бы, какой режим введения местного анестетика необходимо использовать для длительной анальгезии послеоперационной раны, а именно - оптимальные с точки зрения баланса эффективности и безопасности концентрация, объем и скорость введения. 
Таблица 2

\section{Характеристики пациентов и концентрации общего ропивакаина в венозной крови (C) в контрольных точках}

\begin{tabular}{|c|c|c|c|c|c|c|c|c|}
\hline № & $\begin{array}{c}\text { рост, } \\
\text { см }\end{array}$ & $\begin{array}{c}\text { масса } \\
\text { тела, } \\
\text { кг }\end{array}$ & $\begin{array}{l}\text { ИМТ, } \\
\text { кг/м2 }\end{array}$ & $\begin{array}{c}\text { возраст, } \\
\text { лет }\end{array}$ & $\begin{array}{c}\text { С, мкг/мл; } \\
\text { (ропива- } \\
\text { каин 20 мг, } \\
30 \text { мин) } \\
\end{array}$ & $\begin{array}{c}\text { С, мкг/мл; } \\
\text { (ропива- } \\
\text { каин 200 } \\
\text { мг, 24 ч) }\end{array}$ & $\begin{array}{c}\text { С, мкг/мл; } \\
\text { (ропива- } \\
\text { каин 400 } \\
\text { мг, } 48 \text { ч) } \\
\end{array}$ & $\begin{array}{c}\text { Полученная } \\
\text { доза мг/кг }\end{array}$ \\
\hline 1 & 164 & 67 & 24,9 & 38 & 0,034 & & & 0,3 \\
\hline 2 & 167 & 72,3 & 25,9 & 33 & 0,044 & & & 0,3 \\
\hline 3 & 162 & 76 & 29,0 & 45 & 0,018 & & & 0,3 \\
\hline 4 & 158 & 69,6 & 27,9 & 32 & 0,007 & & & 0,3 \\
\hline 5 & 164 & 67 & 24,9 & 30 & 0,024 & & & 0,3 \\
\hline 6 & 155 & 58,3 & 24,3 & 34 & 0,019 & & & 0,3 \\
\hline 7 & 170 & 81,8 & 28,3 & 41 & 0,006 & & & 0,2 \\
\hline 8 & 172 & 76,4 & 25,8 & 32 & & 0,050 & & 2,6 \\
\hline 9 & 164 & 82 & 30,5 & 34 & & 0,043 & & 2,4 \\
\hline 10 & 159 & 56,7 & 22,4 & 33 & & 0,029 & & 3,5 \\
\hline 11 & 173 & 94,3 & 31,5 & 37 & & 0,041 & & 2,1 \\
\hline 12 & 167 & 85 & 30,5 & 30 & & 0,049 & & 2,4 \\
\hline 13 & 166 & 74 & 26,9 & 26 & & 0,073 & & 2,7 \\
\hline 14 & 163 & 69,5 & 26,2 & 31 & & 0,038 & & 2,9 \\
\hline 15 & 177 & 82 & 26,2 & 25 & & 0,009 & & 2,4 \\
\hline 16 & 161 & 63 & 24,3 & 35 & & & 0,087 & 6,3 \\
\hline 17 & 164 & 67,1 & 24,9 & 30 & & & 0,078 & 6,0 \\
\hline 18 & 168 & 78,6 & 27,8 & 47 & & & 0,063 & 5,1 \\
\hline 19 & 167 & 94,1 & 33,7 & 37 & & & 0,053 & 4,3 \\
\hline 20 & 164 & 93,3 & 34,7 & 34 & & & 0,051 & 4,3 \\
\hline 21 & 168 & 73 & 25,9 & 30 & & & 0,030 & 5,5 \\
\hline 22 & 169 & 68,3 & 23,9 & 32 & & & 0,034 & $\begin{array}{l}5,9 \\
\end{array}$ \\
\hline
\end{tabular}

Таблица 3

Зависимость между антропометрическими параметрами пациента (рост-Р, масса тела-М, индекс массы тела-ИМТ) и концентрациями ропивакаина в крови после введения 20 мг - 20,200 мг - $C_{200}$ и 400 мг - 4400 ; коэффициент корреляции Спирмена -r, значение р)

\begin{tabular}{|l|c|c|}
\hline & $\mathbf{r}$ & $\mathbf{p}$ \\
\hline $\mathrm{UMT} / \mathrm{C}_{20}$ & -0.559 & 0.192 \\
\hline $\mathrm{P} / \mathrm{C}_{20}$ & 0.126 & 0.788 \\
\hline $\mathrm{M} / \mathrm{C}_{20}$ & -0.45 & 0.310 \\
\hline $\mathrm{UMT} / \mathrm{C}_{200}$ & 0.277 & 0.506 \\
\hline $\mathrm{P} / \mathrm{C}_{200}$ & 0.0238 & 0.977 \\
\hline $\mathrm{M} / \mathrm{C}_{200}$ & 0.12 & 0.778 \\
\hline $\mathrm{hMT} / \mathrm{C}_{400}$ & -0.143 & 0.783 \\
\hline $\mathrm{P} / \mathrm{C}_{400}$ & -0.709 & 0.0743 \\
\hline $\mathrm{M} / \mathrm{C}_{400}$ & -0.429 & 0.354 \\
\hline
\end{tabular}

Крайне немногочисленны исследования, дающие представление о скорости всасывания ропивакаина при введении его в послеоперационную рану [15].

Опубликованы исследования фармакокинетики ропивакаина при его внутри- венном [2], эпидуральном [17-19] введении, при инстилляции в поперечное пространство живота [6], результаты которых, можно учитывать при выборе схемы введения анестетика в рану, однако Р.Н. Rosenberg, et al. [3] считают, что дозы MA 
должны быть специфицированы для конкретной блокады и выбранного участка ввиду того, что васкуляризация тканей в области введения препарата является основной детерминантой системного всасывания местных анестетиков [4,5].

В нашем исследовании зафиксированные концентрации общего ропивакаина венозной крови виде медианы $\mathrm{Me}(\mathrm{Q} 1 ; \mathrm{Q} 3)$ через 30 мин $=0,019(0,013 ; 0,029)$ мкг/мл, через 24 ч $=0,042(0,036 ; 0,049)$ мкг/мЛ, через 48 ч=0,053 $(0,043 ; 0,071)$ мкг/мл были значительно ниже значений, установленных в предыдущих экспериментах как минимально токсические 2,2 (0,5-3,2) мкг/мл [2]. Вероятно, столь низкие концентрации можно объяснить консервативной схемой введения препарата: низкая концентрация раствора, малая скорость. Также в части случаев имела место утечка раствора через края раны, значение которой сложно оценить.

Безопасность более высоких концентраций общего ропивакаина венозной крови продемонстрировал в подобном исследовании Corso в 2007г. После лапаротомии по поводу колоректального рака в мышечный слой вводился болюс 30 мл 0,75\% раствора ропивакаина, с последующей инфузией через раневой катетер $0,2 \%$ раствора ропивакаина со скоростью 5 мл/час при помощи эластомерной помпы на протяжении 96 часов. Максимальная общая концентрация ропивакаина составила 4,5 +- 2,6 (2,3-8,8) мг/л, однако не было зафиксировано ни одного случая проявления системной токсичности МА. Недостатком исследования можно считать малый объем выборки - участвовало всего 5 пациентов [15]. Тем не менее такие результаты позволяют нам задуматься о применении растворов МА более высоких концентраций или увеличении скорости инфузии. Так в российском исследовании 2015 г. при внутрисуставном введении $0,2 \%$ раствора ропивакаина со скоростью 6-8 мл/ч уровень общего ропивакаина составлял через 30 мин - 0,696 $\pm 0,2$ мкг/мл, через 4-6 ч - 1,58 \pm 0, мкг/мл, через 24 ч $1,039 \pm 0,04$ мкг/мл [16].
Скорость 10 мл/ч также нередко используется для послеоперационной внутрираневой анальгезии в различных областях хирургии. После срединной лапаротомии в колопроктологии. $0,2 \%$ ропивакаин вводился на протяжении 48 ч [20]. Riff, Guilhaumou, Marsot, et al. после односторонней мастэктомии вводили болюс 10 мл $0,75 \%$ ропивакаина с последующей инфузией 400 мл $0,2 \%$ раствора через мультиперфорированный катетер, помещенный на большую грудную мышцу. Средняя

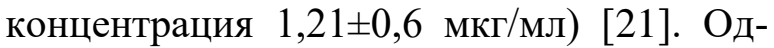
нако авторами не сообщается, имело ли место истечение «излишков» раствора, не подвергшегося всасыванию, на поверхность раны из-за высоких темпов инфузии.

Вопрос о максимальной продолжительности введения МА также остается открытым. Во время длительного (120 ч) непрерывного введения ропивакаина в эпидуральное пространство измерялась общая и свободная концентрация препарата в плазме 12 пациентов, которым была выполнена пластика коленного сустава. Средняя скорость инфузии ропивакаина $0,2 \%$ была $14,6 \pm 3,2$ мл в час в день опера-

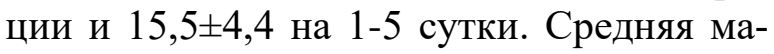
кисмальная общая концентрация препарата составила $4,1 \pm 1,2$ мкг/мл, она была достигнута через $67,7 \pm 16,5$ ч [18].

Описание клинического случая непрерывного эпидурального введения ропивакаина 0,56 мг/кг/ч в течение 192 ч у 7-летнего пациента с травмой после выполнения гильотинной ампутации нижних конечностей. Забор венозной крови через 8 дней выявил концентрации связанного и несвязанного ропивакаина в плазме 1,1 мг / л и 0,06 мг / л соответственно. В этом случае длительное эпидуральное введение ропивакаина в высоких дозах не привело к серьезным побочным эффектам или осложнениям [19].

\section{Заключение}

Данное исследование позволило подтвердить безопасность выбранной схемы введения раствора местного анестетика, т.к. потенциально токсичные концентрации общего ропивакаина в венозной крови не 
были достигнуты ни у одного из пациентов, включенных в исследование, а также не было зафиксировано клинических признаков системной токсичности МА. Более того, значения, полученные исследователями при использовании других, более «агрессивных» схем введения МА, значительно превосходят максимальные концентрации, полученные в нашем исследовании.

Учитывая данные результаты, в дальнейшем возможно рассмотреть использование более высоких концентрации раствора и/или объем и скорость его введения для достижения более высокого уровня анальгезии без ущерба для безопасности.

\section{Дополнительная информация}

Конфликт интересов. Авторы декларируют отсутствие явных и потенциальных конфликтов интересов, о которых необходимо сообщить в связи с публикацией данной статьи.

Этика. В исследовании использованы данные людей в соответствии с подписанным информированным согласием.

Финансирование. Исследование не имело спонсорской поддержки.

\section{Участие авторов:}

Сбор материала, написание текста - Винокурова А.А. M.A.

Лабораторные исследования - Гофенберг

Статистическая обработка - Багин В.А.

Руководство и редактирование - Руднов В.А., Дубровин С.Г.

\section{Литература}

1. Винокурова А.А., Руднов В.А., Дубровин С.Г. Анальгезия послеоперационной раны растворами местных анестетиков // Вестник анестезиологии и реаниматологии. 2019. Т. 16, №4. С. 47 55. doi:10.21292/2078-5658-2019-16-4-47-55

2. Knudsen K., Suurküla M.B., Blomberg S., et al. Central nervous and cardiovascular effects of i.v. infusions of ropivacaine, bupivacaine and placebo in volunteers // British Journal of Anaesthesia. 1997. Vol. 78, №5. P. 507-514. doi:10.1093/bja/78.5.507

3. Rosenberg P.H., Veering B.T., Urmey W.F. Maximum recommended doses of local anesthetics: a multifactorial concept // Regional Anesthesia and Pain Medicine. 2004. Vol. 29, №6. P. 564-575. doi:10.1016/j.rapm.2004.08.003

4. Karatassas A., Morris R.G., Slavotinek A.H. The relationship between blood flow and absorption of lignocaine // The Australian and New Zealand Journal of Surgery. 1993. Vol. 63, №10. P. 766-771. doi:10.1111/j.1445-2197.1993.tb00338.x

5. Morris R.G., Karatassas A., Orfanos A. Regional blood flow as a determinant of drug pharmacokine-tics - description of an animal model // Journal of Pharmacological and Toxicological Methods. 1993. Vol. 30, №1. P. 39-45. doi:10.1016/1056-8719(93)90006-Z

6. Rahiri J., Tuhoe J., Svirskis D., et al. Systematic review of the systemic concentrations of local anaesthetic after transversus abdominis plane block and rectus sheath block // British Journal of Anaesthesia. 2017. Vol. 118, №4. P. 517-526. doi:10.1093/bja/aex005

7. ASA Physical Status Classification System. 2014. Available at: file:///C:/Users/User/Downloads/asaphysical-status-classification-system.pdf. Accessed: 2020 April 08.

8. Серов В.Н., Адамян Л.В., Филиппов О.С., и др. Кесарево сечение. Показания, методы обезбо-ливания, хирургическая техника, антибиотикопрофилактика, ведение послеоперационного пери- ода. Клинические рекомендации (протокол). 2014. Доступно по: https://amurzdrav.ru/ftp/deti/ docs/Клинический\%20протокол\%20Кесарево $\%$ 20сечение.pdf. Ссылка активна на 08 апреля 2020.

9. Gupta A., Favaios S., Perniola A., et al. A metaanalysis of the efficacy of wound catheters for postoperative pain management // Acta Anaesthesiologica Scandinavica. 2011. Vol. 55, №7. P. 785-796. doi:10.1111/j.1399-6576.2011.02463.x

10. Liu S.S., Richman J.M., Thirlby R.C., et al. Efficacy of continuous wound catheters delivering local anesthetic for postoperative analgesia: a quantitative and qualitative systematic review of randomized controlled trials // Journal of the American College of Surgeons. 2006. Vol. 203, №6. P. 914-932. doi:10.1016/j.jamcollsurg.2006.08.007

11. Johnson S.M., Saint John B.E., Dine A.P. Local anesthetics asantimicrobial agents: a review // Surgical Infections. 2008. Vol. 9, №2. P. 205-213. doi:10.1089/sur.2007.036

12. Kaewjiaranai T., Srisatjaluk R.L., Sakdajeyont W., et al. The efficiency of topical anesthetics as antimicrobial agents: A review of use in dentistry // Journal of Dental Anesthesia and Pain Medicine. 2018. Vol. 18, №4. P. 223-233. doi:10.17245/ jdapm.2018.18.4.223

13. Razavi B.M., Bazzaz B.S.F. A review and new insights to antimicrobial action of local anesthetics // European Journal of Clinical Microbiology \& Infectious Diseases. 2019. Vol. 38, №6. P. 991-1002. doi:10.1007/s10096-018-03460-4

14. Stratford A.F., Zoutman D.E., Davidson J.S. Effect of lidocaine and epinephrine on Staphylococcus aureus in a guinea pig model of surgical wound infection // Plastic and Reconstructive Surgery. 2002. Vol. 110, №5. P. 1275-1279. doi:10.1097/01.PRS. $0000025427.86301 .8 \mathrm{~A}$

15. Corso O.H., Morris R.G., Hewett P.J., et al. Safety of 96-hour incision-site continuous infusion of ropivacaine 
for postoperative analgesia after bowel cancer resection // Therapeutic Drug Monitoring. 2007. Vol. 29, №1. P. 57-63. doi:10.1097/FTD.0b013e3 1802c59ec

16. Корячкин В.А., Гераськов Е.В., Коршунов Д.Ю. Оценка безопасности инфильтрационной анестезии при тотальном эндопротезировании коленного сустава // Новости хирургии. 2015. Т. 23, №4. C. 436-439. doi:10.18484/2305-0047. 2015.4.436

17. Lee B.B., Ngan Kee W.D., Plummer J.L., et al. The Effect of the Addition of Epinephrine on Early Systemic Absorption of Epidural Ropivacaine in Humans // Anesthesia and Analgesia. 2002. Vol. 95, №5. P. 1402-1407. doi:10.1097/00000539-200211000-00055

18. Wiedemann D., Mühlnickel B., Staroske E., et al. Ropivacaine plasma concentrations during 120hour epidural infusion // British Journal of Anaesthesia. 2000. Vol. 85, №6. P. 830-835. doi:10.1093/ bja/85.6.830

19. Van de Vossenberg G., van der Wal S., Müller A., et al. Ropivacaine Plasma Concentrations after 192Hour High Dose Epidural Ropivacaine Infusion in a Pediatric Patient without Side Effects // Case Reports in Anesthesiology. 2018. Vol. 2018. P. 9150980. doi:10.1155/2018/9150980

20. Beaussier M., El'Ayoubi H., Schiffer E., et al. Continuous preperitoneal infusion of ropivacaine provides effective analgesia and accelerates recovery after colorectal surgery: a randomized, doubleblind, placebo-controlled study // Anesthesiology. 2007. Vol. 107, №3. P. 461-468. doi:10.1097/01. anes.0000278903.91986.19

21. Riff C., Guilhaumou R., Marsot A., et al. Ropivacaine wound infiltration for pain management after breast cancer mastectomy: a population pharmacokinetic analysis // Clinical Pharmacology in Drug Development. 2018. Vol. 7, №8. P. 811-819. doi:10.1002/cpdd.452

\section{References}

1. Vinokurova AA, Rudnov VA, Dubrovin SG. Analgesia of post-operative wound with local anesthetics. Messenger of Anesthesiology and Resuscitation. 2019;16(4):47-55. (In Russ). doi:10.21292/ 2078-5658-2019-16-4-47-55

2. Knudsen K, Suurküla MB, Blomberg S, et al. Central nervous and cardiovascular effects of i.v. infusions of ropivacaine, bupivacaine and placebo in volunteers. British Journal of Anaesthesia. 1997; 78(5):507-14. doi:10.1093/bja/78.5.507

3. Rosenberg PH, Veering BT, Urmey WF. Maximum recommended doses of local anesthetics: a multifactorial concept. Regional Anesthesia and Pain Medicine. 2004;29(6):564-75. doi:10.1016/j.rapm. 2004.08.003

4. Karatassas A, Morris RG, Slavotinek AH. The relationship between blood flow and absorption of lignocaine. The Australian and New Zealand Journal of Surgery. 1993;63(10):766-71. doi:10.1111/j. 1445-2197.1993.tb00338.x

5. Morris RG, Karatassas A, Orfanos A. Regional blood flow as a determinant of drug pharmacokinetics - description of an animal model. Journal of
Pharmacological and Toxicological Methods. 1993; 30(1):39-45. doi:10.1016/1056-8719(93)90006-z

6. Rahiri J, Tuhoe J, Svirskis D, et al. Systematic review of the systemic concentrations of local anaesthetic after transversus abdominis plane block and rectus sheath block. British Journal of Anaesthesia. 2017;118(4):517-26. doi:10.1093/bja/aex005

7. ASA Physical Status Classification System. 2014. Available at: file:///C:/Users/User/Downloads/asaphysical-status-classification-system.pdf. Accessed: 2020 April 08.

8. Serov VN, Adamyan LV, Filippov OS, et al. Kesarevo secheniye. Pokazaniya, metody obezbolivaniya, khirurgicheskaya tekhnika, antibiotiko-profilaktika, vedeniye posleoperatsionnogo perioda. Klinicheskiye rekomendatsii (protokol). 2014. Available at: https://amurzdrav.ru/ftp/deti/docs/ Клинический\%20протокол\%20Кесарево\%20сечение.pdf. Accessed: 2020 April 08. (In Russ).

9. Gupta A, Favaios S, Perniola A, et al. A meta-analysis of the efficacy of wound catheters for post-operative pain management. Acta Anaesthesiologica Scandinavica. 2011;55(7):785-96. doi:10.1111/j. 1399-6576.2011.02463.x

10. Liu SS, Richman JM, Thrilby RC, et al. Efficacy of continuous wound catheters delivering local anesthetic for postoperative analgesia: a quantitative and qualitative systematic review of randomized controlled trials. Journal of the American College of Surgeons. 2006;203(6):914-32. doi:10.1016/j.jam collsurg.2006.08.007

11. Johnson SM, Saint John BE, Dine AP. Local anesthetics asantimicrobial agents: a review. Surgical Infections. 2008;9(2):205-13. doi:10.1089/sur.2007.036

12. Kaewjiaranai T, Srisatjaluk RL, Sakdajeyont W, et al. The efficiency of topical anesthetics as antimicrobial agents: A review of use in dentistry. Journal of Dental Anesthesia and Pain Medicine. 2018;18 (4):223-33. doi:10.17245/ jdapm.2018.18.4.223

13. Razavi BM, Bazzaz BSF. A review and new insights to antimicrobial action of local anesthetics. European Journal of Clinical Microbiology \& Infectious Diseases. 2019;38(6):991-1002. doi:10.1007/ s10096-018-03460-4

14. Stratford AF, Zoutman DE, Davidson JS. Effect of lidocaine and epinephrine on Staphylococcus aureus in a guinea pig model of surgical wound infection. Plastic and Reconstructive Surgery. 2002; 110(5):1275-9. doi:10.1097/01.PRS.0000025427.86301.8A

15. Corso OH, Morris RG, Hewett PJ, et al. Safety of 96-hour incision-site continuous infusion of ropivacaine for postoperative analgesia after bowel cancer resection. Therapeutic Drug Monitoring. 2007;29 (1):57-63. doi:10.1097/FTD.0b013e31802c59ec

16. Koryachkin VA, Geraskov VV, Korshunov DY. Evaluation of Infiltration Anesthesia Safety in Total Knee Joint Arthroplasty. Novosti Khirurgii. 2015; 23(4):436-9. (In Russ). doi:10.18484/2305-0047. 2015.4.436

17. Lee BB, Ngan Kee WD, Plummer JL, et al. The Effect of the Addition of Epinephrine on Early 
Systemic Absorption of Epidural Ropivacaine in Humans. Anesthesia and Analgesia. 2002;95(5): 1402-7. doi:10.1097/00000539-200211000-00055

18. Wiedemann D, Mühlnickel B, Staroske E, et al. Ropivacaine plasma concentrations during 120hour epidural infusion. British Journal of Anaesthesia. 2000;85(6):830-5. doi:10.1093/bja/85.6.830

19. Van de Vossenberg G, van der Wal S, Müller A, et al. Ropivacaine Plasma Concentrations after 192Hour High Dose Epidural Ropivacaine Infusion in a Pediatric Patient without Side Effects. Case Reports in Anesthesiology. 2018;2018:9150980. doi:10.1155/2018/9150980
20. Beaussier M, El'Ayoubi H, Schiffer E, et al. Continuous preperitoneal infusion of ropivacaine provides effective analgesia and accelerates recovery after colorectal surgery: a randomized, doubleblind, placebo-controlled study. Anesthesiology. 2007;107(3):461-8. doi:10.1097/01.anes.00002789 03.91986 .19

21. Riff C, Guilhaumou R, Marsot A, et al. Ropivacaine wound infiltration for pain management after breast cancer mastectomy: a population pharmacokinetic analysis. Clinical Pharmacology in Drug Development. 2018;7(8):811-9. doi:10.1002/cpdd.452

\section{Информация об авторах [Authors Info]}

*Винокурова Анна Анатольевна - врач анестезиолог реаниматолог отделения анестезиологии и реанимации №2, Европейский медицинский центр «УГМК-Здоровье»; аспирант кафедры анестезиологии, реаниматологии, токсикологии и трансфузиологии, Уральский государственный медицинский университет, Екатеринбург, Российская Федерация. e-mail: 89089232467@ yandex.ru SPIN: 9118-1807, ORCID ID: 0000-0003-4621-8577.

Anna A. Vinokurova - Anesthesiologist-Resuscitator of Anesthesiology and Resuscitation Unit №2, European Medical Center USMC-Health, PhD-student of the Department of Anesthesiology, Resuscitation, Toxicology and Transfusionology, Ural State Medical University, Ekaterinburg, Russian Federation.e-mail: 89089232467@yandex.ru SPIN: 9118-1807, ORCID ID: 0000-0003-4621-8577.

Гофенберг Мария Александровна - зав. химико-токсикологической лабораторией, Областная наркологическая больница; провизор-аналитик химико-токсикологической лаборатории, Свердловская областная клиническая психиатрическая больница; ассистент кафедры фармации и химии, Уральский государственный медицинский университет, Екатеринбург, Российская Федерация.

SPIN: 8396-2390, ORCID ID: 0000-0003-2877-1301.

Maria A. Hofenberg - Head of Chemical Toxicological Laboratory, Regional Narcological Hospital; Pharmacist-Analyst of Chemical Toxicological Laboratory, Sverdlovsk Regional Clinical Psychiatric Hospital; Assistant of the Department of Pharmacy and Chemistry, Ural State Medical University, Ekaterinburg, Russian Federation.

SPIN: 8396-2390, ORCID ID: 0000-0003-2877-1301.

Дубровин Сергей Германович - к.м.н., зав. отделением анестезиологии и реанимации №2, Городская клиническая больница №40, Екатеринбург, Российская Федерация.

ORCID ID: 0000-0003-3320-9831.

Sergey G. Dubrovin - MD, PhD, Head of Anesthesiology and Resuscitation Unit №2, Municipal Clinical Hospital №40, Ekaterinburg, Russian Federation.

ORCID ID: 0000-0003-3320-9831.

Багин Владимир Анатольевич - к.м.н., зав. отделением анестезиологии и реанимации №5, Городская клиническая больница №40, Екатеринбург, Российская Федерация.

SPIN: 2190-6891, ORCID ID: 0000-0002-5290-1519.

Vladimir A. Bagin - MD, PhD, Head of Anesthesiology and Resuscitation Unit №5, Municipal Clinical Hospital №40, Ekaterinburg, Russian Federation.

SPIN: 2190-6891, ORCID ID: 0000-0002-5290-1519.

Руднов Владимир Александрович - д.м.н., профессор кафедры анестезиологии, реаниматологии, токсикологии и трансфузиологии, Уральский государственный медицинский университет; зам. главного врача по службе анестезиологии и реаниматологии, Городская клиническая больница №40, Екатеринбург, Российская Федерация.

ORCID ID: 0000-0003-0830-786X.

Vladimir A. Rudnov - MD, PhD, Professor of the Department of Anesthesiology, Resuscitation, Toxicology and Transfusionology, Ural State Medical University; Deputy Chief Medical Officer for Anesthesiology and Resuscitation Service, Municipal Clinical Hospital №40, Ekaterinburg, Russian Federation.

ORCID ID: 0000-0003-0830-786X

Цитировать: Винокурова А.А., Гофенберг М.А., Дубровин С.Г., Багин В.А., Руднов В.А. Определение концентрации ропивакаина в венозной крови при проведении длительной анальгезии послеоперационной раны // Наука молодых (Eruditio Juvenium). 2020. T. 8, №4. C. 555-565. doi:10.23888/HMJ202084555-565

To cite this article: Vinokurova AA, Gofenberg MA, Dubrovin SG, Bagin VA, Rudnov VA. Determination of concentration of ropivacaine in venous blood in prolonged analgesia of postoperative wound. Science of the young (Eruditio Juvenium). 2020;8(4):555-65. doi:10.23888/ HMJ202084555-565 